\title{
Mengkritisi Teologi Sekularisasi
}

\author{
Sonny Eli Zaluchu \\ Program Studi Pascasarjana Sekolah Tinggi Theologia Baptis Indonesia Semarang \\ gloryofgodmin@gmail.com
}

\begin{abstract}
The theology of secularization was a product of a changing age that was triggered by a shift in philosophical thought at the time of enlightenment. Rationalism put human hegemony over dogmatic issues so that theology also ought to be able to answer a changing need for the postmodern era. This article aimed to show a reflection presented by secularisation theology in post-liberalism. The method used was descriptive historical, to explain the theology of secularization in the context of changes and needs of modern humans until today. The conclusion is that secularization theology is an actualization of modern thought that seeks to apply the values of Christianity in the context of a wider world, independent of its religious and dogmatic hegemony.
\end{abstract}

\begin{abstract}
Abstrak
Teologi sekularisasi merupakan produk dari sebuah perubahan jaman yang dipicu oleh pergeseran pemikiran filsafat pada masa pencerahan. Rasionalisme mengembalikan hegemoni manusia di atas persoalan dogmatis, sehingga teologi juga harus dapat menjawab sebuah kebutuhan jaman yang sedang menuju ke arah posmodern. Artikel ini bertujuan untuk menunjukkan sebuah refleksi yang dihadirkan oleh pemikiran teologi sekularisasi pada masa post-liberalisme. Metode yang digunakan adalah deskriptif historis, untuk menjelaskan tentang teologi sekularisasi pada konteks perubahan dan kebutuhan manusia jaman modern hingga saat ini. Sebagai kesimpulan, teologi sekularisasi merupakan aktualisasi pemikiran modern yang mencoba menerapkan nilai-nilai kekristenan dalam konteks dunia yang lebih luas, yang terlepas dari hegemoni agama dan dogmatikanya.
\end{abstract}

\section{Article History}

Submit:

13 Februari 2018

Accept:

02 April 2018

Publish:

11 April 2018

Keywords:

church; modern world; teologi of secularization; religious

\section{Kata kunci:}

dunia modern; gereja; religius; teologi sekularisasi 


\section{Pendahuluan}

Sekularisasi berawal dari perkembangan peradaban manusia yang semakin modern. Percepatan dan kemajuan di dalam banyak hal, seperti teknologi, ilmu pengetahuan dan sistem kemasyarakatan, telah mempercepat dan memperkuat sekularisasi. Muncul sebuah generasi yang beranggapan bahwa hal-hal yang berbau agama dan moral sudah tidak relevan lagi dalam menjawab berbagai isu-isu kemasyarakatan yang ada ${ }^{1}$. Sebelum sekularisasi, orang mendapat jawaban dari berbagai pertanyaan melalui agama, tetapi dengan sekularisasi, pengetahuan menjadi satu-satunya acuan dan penjawab berbagai persoalan masyarakat yang ada.

Era sekularisasi ditandai dengan bangkitnya akal budi manusia dalam memberi penjelasan atas berbagai realitas kehidupan manusia. Dengan demikian, sekularisasi sekaligus melahirkan respon manusia yang kritis terhadap agama dan kekristenan. Orang mulai berorientasi pada hal-hal yang duniawi, yang ada di dalam dunia ini dari pada urusan supernatural di dalam gereja. Akibatnya, pandangan orang mengenai iman Kristen mulai berubah dan mengalami pergeseran. Masyarakat berpaling pada asas-asas ideologi lain sebagai sebuah tanggap sejarah atas perkembangan pemikiran baru di tengah arus modernitas. Salah satu penyebabnya adalah struktur pembentukan masyarakat Barat yang di awali dengan berbagai pra-anggapan yang sekular (non-keagaamaan) di mana aktivitas beragama dipandang sebagai sebuah pilihan yang sangat pribadi bagi individu. ${ }^{2}$

Di belahan dunia Barat, khususnya Eropa, terjadi perubahan radikal yang dipengaruhi oleh perubahan pemikiran filsafat. Masa kejayaan abad pertengahan begitu cepat memudar dengan hadirnya renaisance sebagai pembuka kepada Rasionalisme dan Empirisme; kedua aliran terakhir memicu lahirnya era pencerahan (enlightenment). Orang lebih cenderung melakukan aktivitas sosial sebagai wujud kepercayaan dan aplikasi imannya dari pada menghabiskan waktu berbicara tentang hal-hal yang supra-natural di dalam gereja. Masyarakat berubah menjadi lebih pluralis dalam menanggapi persoalan-persoalan agama. ${ }^{3}$

\section{Sekularisasi, Sekularisme dan Posisi Agama}

Sekularisasi tidak muncul dengan sendirinya; ia lahir sebagai bagian dari sejarah perkembangan peradaban, pertama-tama di Eropa kemudian di Barat. Era pencerahan yang hadir oleh perubahan arah berpikir filsafat, juga telah memicu perubahan nuansa dan orientasi berteologi. Kehadiran Renaisance telah memicu sebuah gerakan reformasi; hal ini sekaligus

\footnotetext{
${ }^{1}$ David L. Smith, A Handbook of Contempporary Theology (Grand Rapids: Baker Books, 1992), 165.

${ }^{2}$ Tony Lane, Runtut Pijar Sejarah Pemikiran Kristiani (Jakarta: BPK Gunung Mulia, 2005), 197.

${ }^{3}$ Ibid.
} 
menandai berakhirnya hegemoni agama (dogma), dan mengembalikan kekuasaannya pada manusia sebagai penentu. Gelombang dinamis ini pun akhirnya menghadapkan sebuah pilihan kepada gereja (teologi) dalam menyikapinya; mendorong orang untuk menafsirkan kembali dogmatika iman Kristen agar relevan terhadap perubahan yang sedang dialami dunia. ${ }^{4}$ Proses yang dimulai dari konflik antara akal (rasionalitas) dan tanggapan iman Kristiani yang dianggap tidak lagi relevan terhadap perkembangan ilmu pengetahuan, akhirnya berujung pada sikap untuk membawa teologi keluar dari gereja dan menemukan panggilannya di tengah dunia sekular.

Pada abad pertengahan (middle ages), gereja terlihat sangat mendominasi peradaban Barat. Tetapi, seiring dengan perubahan dan semakin majunya teknologi, ilmu pengetahuan dan kebudayaan, masyarakat berkembang dan dunia melahirkan hal-hal baru. Terjadi benturan yang sangat keras antara perubahan dunia yang begitu cepat dengan sikap gereja yang sangat ortodoks terutama dalam hal penelitian ilmiah. Gereja dan ajarannya justru dianggap gagal menyesuaikan diri terhadap perubahan dan dianggap menghambat kemajuan penelitian ilmiah. Perkembangan di dalam dunia ilmu pengetahuan muncul teori Evolusi Darwin yang telah menggugat banyak hal ajaran gereja soal penciptaan. Sebagai akibatnya, muncul pertentangan yang sangat kontras antara akal dan Injil. Itu sebabnya sejarah zaman pertengahan itu disebut zaman kegelapan (dark ages).

Tetapi pasca abad pertengahan, terjadi perkembangan radikal di Eropa yang kemudian berjalan ke Barat. Muncul gerakan kelahiran baru (renaissance) di abad ke-15 dan ke-16 dan fokus gerakan ini sama sekali membebaskan akal dari pengaruh Injil dan ortodoksi gereja. Akal tidak lagi ditempatkan sebagai sub-ordinasi dari Alkitab dan ajaran-ajaran dogmatik gereja. Terlebih abad ke-17 hingga abad ke-19, arus modernisasi sangat tidak bisa dibendung lagi. ${ }^{5}$ Ajaran-ajaran gereja mulai ditinggalkan sebagai satu-satunya sumber pemikiran merespon modernitas.

Kemudian, muncul semangat rasionalisasi di Barat yang dimotori oleh filsuf, teolog, sosiolog, psikolog, sejarawan, politikus dan lain-lainnya menulis tentang berbagai karya yang menitikberatkan aspek kemanusiaan, kebebasan, dan keadilan. Mereka membebaskan sektorsektor di dalam masyarakat dan kebudayaan yang ada dari dominasi lembaga-lembaga dan simbol keagamaan. Inilah proses yang kemudian oleh Peter L. Berger disebut sebagai

\footnotetext{
${ }^{4}$ Fauzan, "SEKULARISASI DALAM PANDANGAN HARVEY COX," Kalam: Jurnal Studi Agama dan Pemikiran Islam Vol 6, no. 2 (2012): 251-272.

${ }^{5}$ Halim Wiryadinata, “An Evaluation Of Liberation Theology in The Light Of Its Praxis," KURIOS (Jurnal Teologi dan Pendidikan Agama Kristen) 1, no. 1 (2013): 1-10.
} 
sekularisasi. ${ }^{6}$ Posisi gereja dan ajarannya menjadi terpinggirkan dan dianggap sebagai urusan pribadi setiap manusia yang tidak memiliki kaitan dengan persoalan dunia dan kemasyarakatan. Manusia menjadi cenderung bersandar pada diri sendiri daripada mitos kuno dan ketuhanan yang ada di dalam agama. ${ }^{7}$

Karel Dobbelaere berpendapat bahwa sekularisasi adalah suatu proses dalam masyarakat yang telah mengalami perubahan-perubahan struktural, di mana suatu sistem keagamaan yang transenden dan mencakup segalanya disusutkan menjadi suatu sub-sistem dari masyarakat yang ada bersama subsistem-subsistem lainnya; proses ini membuat klaimklaim tentang pencakupan segalanya itu kehilangan relevansinya. Dengan demikian, lembaga agama termarjinalisasikan dan terprivatisasi ${ }^{8}$. Dengan kata lain, aturan-aturan keagamaan tradisional, atau norma-norma yang didasarkan pada nilai-nilai keagamaan, akan semakin digantikan oleh norma-norma sekular atau betul-betul tersingkir, menjadi tidak dapat dipakai di dalam subsistem-subsistem pendidikan, keluarga, politik, ekonomi, dan sains, yang berbeda-beda 9 .

Sekularisasi berbeda dengan sekularisme. Pengertian yang sangat radikal dari sekularisme adalah sebuah upaya penolakan atau pengusiran agama dan pemikiran religius dari kehidupan manusia. Bahkan dapat mengarah pada usaha untuk menyangkal Tuhan seutuhnya (atheis). Pusat kehidupan sepenuhnya adalah dunia ini melalui akal budi manusia. Sekularisme menekankan pada usaha yang menggeser bahkan menyingkirkan Allah dari realitas kehidupan. Akibatnya, Allah tidak lagi dipandang sebagai sesuatu yang ada, Allah menjadi sesuatu yang abstrak dan tak terjangkau; sebaliknya, segala sesuatu dianggap lahir dari proses alamiah, natural; atau, sebagai proses yang berlangsung dalam dunia ini, yang dapat dipahami secara rasional berkat kemampuan akal budi manusia yang melahirkan kemajuan ilmu pengetahuan dan teknologi. Bedanya dengan sekularisasi adalah posisi agama yang masih diakui walau tidak lagi mendapat peran publik. Sekularisasi tidak langsung menyangkal eksistensi Allah dan tetap menginjinkan seseorang memeluk agamanya secara pribadi. Keyakinan seseorang melalui agamanya tidak boleh mencampuri berbagai persoalan yang ada di tengah masyarakat.

\footnotetext{
${ }^{6}$ Peter L. Berger, The Sacred Canopy: Elements of A Sociological Theory of Religion (New York: Doubleday \& Company, 1969), 107.

${ }^{7}$ Fauzan, "SEKULARISASI DALAM PANDANGAN HARVEY COX."

${ }^{8}$ Karel Dobbelaere, "The Secularization of Society? Some Methodological Suggestions," in Secularization and Fundamentalism Reconsidered: Religion and the Political Order, ed. Jeffrey K. Hadden and Anson Shupe (New York: Paragon House, 1989), 27-44.

${ }^{9}$ Ibid, 38 .
} 


\section{Metodologi}

Metode yang digunakan dalam pembahasan ini adalah deskrptif dan analisis historis. Kemunculan teologi sekularisasi merupakan imbas dari perubahan-perubahan baik dalam dunia filsafat maupun alam pemikiran Kristen. Perubahan-perubahan tersebut merupakan peristiwa historis yang tidak muncul begitu saja, namun memiliki latar belakang yang saling berkaitan satu dengan yang lainnya. Penelitian ini mendeskripsikan peristiwa historis yang memunculkan teologi sekularisasi, yang selanjutnya menganalisis ajarannya menurut nilai iman Kristen, serta mengaktualisasikannya dalam kehidupan Kristen saat ini.

\section{Pembahasan}

Titik tolak teologi sekularisasi adalah munculnya penafsiran baru soal kehidupan kekristenan, di mana gereja harus dapat menghasilkan teologi yang relevan dengan perubahan zaman. Penafsiran baru ini menolak penafsiran lama yang menyatakan bahwa ada alam lain yang lebih hebat dan lebih agamis dari alam ini. Teologi ini adalah hasil dari pemikiran para teolog Barat yang dipengaruhi oleh semangat modernisme yaitu rasionalisme dan sekularisme yang menjadi ciri masyarakatnya pada abad ke-20. Chul Min Jun mengatakan adanya ciri khas teologi yang kompromistis pada era modern terlebih posmodern. ${ }^{10}$ Teologi sekular merupakan ekspresi dari berteologi di era modern atau posmodern, sehingga tendensi kompromistis dan pluralis menjadi konsekuensi logis yang tidak dapat dihindari.

Para teolog ini beranggapan bahwa alam yang lebih nyata dan kerajaan yang sebenarnya adalah realitas yang ada saat ini yaitu dunia. Sebagai milik Allah, manusia bukan berarti tanpa dunia. Manusia tinggal dan berada di dalam dunia dan harus menemukan sikap yang sebenarnya terhadap Allah dan dunia. Sikap yang benar itu adalah membiarkan Allah tetap Allah dan dunia tetap dunia ${ }^{11}$. Sebagai akibat semakin sekulernya masyarakat di zaman modern, terjadi perubahan radikal di dalam memandang gereja, ajarannya dan terhadap kitab suci. Gereja dan otoritas kitab suci mulai dipertanyakan dan beberapa isinya dianggap tidak relevan lagi. Muncul pendekatan baru terhadap kita suci dengan memperlakukannya sebagai produk literer. Dalam anggapan ini, Alkitab diperlakukan sebagai dokumen-dokumen yang lahir dari sejarah. Inilah yang kemudian melahirkan pendekatan yang bersifat kritis-historis terhadap Alkitab. Terdapat banyak tokoh dan teolog yang ikut menggagas teologi sekularisasi

\footnotetext{
${ }^{10}$ Chul Min Jun, “The Paradigm Shift of Practical Theology and Theological Practice to Overcome Modernism and Postmodernism," Pacific Science Review (2015): 1-11.

${ }^{11}$ Harun Hadiwijono, Pemikiran Reformatoris Abad Ke-20 (Jakarta: BPK Gunung Mulia, 2004), 50.
} 
seperti Thomas J.J Altizer, William Hamilton, Gabriel Vahanian dan Richard Rubenstein. ${ }^{12}$ Pokok pikiran mereka mendukung konsep Allah mati di dalam dunia modern. ${ }^{13}$

Salah seorang teolog yang mencoba melakukan pendekatan baru dengan dengan dunia modern adalah Friederich Gogarten (1887), seorang pakar di dalam ilmu teologi. Gogarten memikirkan suatu konfrontasi iman Kristen dengan realitas dunia yang telah berubah menjadi sekuler. Menurutnya, sekularisasi adalah produk iman Kristen sendiri; sebuah gejala postKristen sebagai akibat yang wajar terjadi. Iman Kristen mendorong manusia untuk menguasai dan mengelola bumi. Manusia bukan hanya manusia yang tanpa Allah melainkan juga bukan manusia yang tanpa dunia. Manusia berada di antara Allah dan dunia dan harus menemukan sikap yang sebenarnya terhadap keduanya. Itulah sebabnya Gogarten setuju membiarkan Allah tetap Allah dan manusia tetap manusia.

Gogarten membedakan dua macam sekularisasi. Yang pertama adalah sekularisasi yang tetap terikat pada iman Kristen dan itulah yang harus diperjuangkan. Jangan sampai sekularisasi berubah jadi sekularisme. Sedangkan yang kedua adalah sekularisasi yang melepaskan diri dari iman Kristiani, yang kemudian diistilahkan Sekularisme. Sekularisme merupakan penyelewengan dari sekularisasi. Inilah yang menjadi tugas iman Kristen di dalam teologi sekularisasi, melindungi sekularisasi agar tidak menyeleweng menjadi sekularisme.

Cendikiawan Islam, Nurcholis Madjid, menegaskan bahwa, sekularisasi bukanlah ekspresi sekularisme, melainkan upaya untuk memberikan ruang bagi manusia yang beragama (khalifah) agar dapat bertindak bagi sesamanya. ${ }^{14}$ Sekularisasi membawa orang keluar dari rantai agama, agar dapat berbuat bagi sesamanya, karena dengan demikianlah mereka sesungguhnya akan mempertanggungjawabkan itu kepada Tuhan di kemudian hari. Artinya, sekularisasi mempertegas implikasi kesalehan dalam kehidupan di dunia sekular.

Tokoh kedua yang mendukung teologi sekularisasi ialah Dietrich Bonhoeffer (19061945). Belajar teologi di Union Theological Seminary New York sebelum akhirnya menjadi dosen teologi di Berlin. Ia juga sempat belajar di Universitas Tubingen. Saat kembali ke

\footnotetext{
${ }^{12}$ Smith, A Handbook of Contempporary Theology, 169-172.

${ }^{13}$ F.W. Nietzsche dalam salah satu bagian bukunya Die Frohliche Wissenschaft ("Ilmu Pengetahuan Yang Menggirangkan”) untuk pertama kalinya memproklamasikan mengenai ‘kematian Tuhan'. Di dalam bagian itu, Nietzsche menceritakan seorang gila yang berlari di pasar saat pagi cerah dengan membawa dian di tangannya sambil berseru-seru, "Aku mencari Tuhan! Aku mencari Tuhan!" Orang-orang menertawakannya dan balik bertanya, "Apakah Tuhan hilang atau tersesat seperti anak kecil? Apakah Ia bepergian atau berimigrasio?". Orang gila itu melompak ke tengah-tengah mereka dan berteriak, "Tuhan binasa. Aku berkata kepadamu. Kita telah membunuhNya. Kamu dan aku". Oleh karena orang-orang itu tidak mengerti apa yang dimaksudkannya, ia pergi mengembara ke gedung-gedung gereja di kota dan berteriak: "Apa gedung-gedung gereja ini, jika bukan makan dan nisan-nisan Tuhan?" Pokok pikiran Nietzsche dapat di selami dalam sebuah buku terbaru berjudul "Para Pembunuh Tuhan" yang diterbitkan oleh Kanisius (2009).

${ }^{14}$ Budi Prayetno, "KONSEP SEKULARISASI DALAM PEMIKIRAN NURCHOLISH MADJID," Sulesana: Jurnal Wawasan Keislaman Vol 11, no. 2 (2017): 1-14.
} 
Jerman Bonhoeffer adalah salah seorang penentang Nazi dan arogansi Hitler dengan ras Aryanya. Aktivitas politiknya membuat ia dilarang berbicara di depan umum dan juga menulis atau mengedarkan buku. Ia ditangkap dan dipenjarakan tahun 1943 dan dihukum mati oleh Nazi pada tahun 1945, beberapa hari sebelum Jerman menyerah pada sekutu. Di dalam penjara ia menulis sebuah karya yang terkenal Letters and Papers from Prison.

Pemikiran Bonhoeffer sangat terinspirasi oleh Karl Bath. Ia mendukung pemikiran Gogarten mengenai kemampuan akaliah manusia yang telah berkembang sehingga menjadikan dunia menjadi sekuler. Itu adalah bagian dari sejarah yang mau tidak mau harus disikapi. Dalam pandangannya, sekularisasi telah mengakhiri keberadaan agama. Dalilnya yang terkenal menyebutkan bahwa zaman sekarang ini adalah zaman akhir religi karena sudah bukan zamannya lagi orang dipengaruhi dengan kata-kata yang saleh ${ }^{15}$. Perkembangan moderan adalah perkembangan tanpa ruang bagi religi. Konsepnya itu menghantar pada pemikiran mengenai "Allah adalah mati” dan sangat menekankan kemandirian manusia, satu prinsip sekular tentang ketidakbergantungan manusia terhadap Allah ${ }^{16}$. Sebagai akibatnya, pengertian-pengertian Alkitab yang kita warisi tidak dapat dimengerti lagi oleh orang modern sehingga perlu diberi interpretasi non-religius.

Bonhoeffer berpendapat bahwa manusia harus berbicara tentang Allah secara duniawi dan memberitakan Injil tanpa religi ${ }^{17}$. Tony Lane mengatakan bahwa Bonhoeffer menangkap kesulitan manusia modern untuk memahami Allah, sama halnya ketika manusia juga berusaha memahami soal mujizat. Orang percaya harus menjalankan kehidupan sekuler dan dengan demikian ikut serta dalam penderitaan Allah. Partisipasi dalam penderitaan Allah itulah yang menurut Bonhoeffer sebagai ciri kekristenan, bukan perbuatan keagamaan ${ }^{18}$. Penafsiran sekuler mengenai Allah adalah dengan cara bagaimana membawa Allah dan gereja kembali ke dalam dunia yang sekuler dan membuatnya menjadi pusat kehidupan. Bonhoeffer berteori bahwa "agama" tidaklah dapat diterima. Yang penting adalah bagaimana seseorang berjumpa dengan Kristus dan bukan dengan agama. Inilah yang kemudian memunculkan istilah "kekristenan yang tanpa agama". Sebagian orang beranggapan bahwa maksud Bonhoeffer dapat ditafsirkan sebagai tindakan disiplin di dalam dunia sebagai murid Kristus. Tetapi banyak juga yang beranggapan bahwa Bonhoeffer bermaksud menekankan kemandirian manusia, satu ciri khas manusia dewasa yang tidak lagi hidup bergantung kepada Allah melalui ilmu pengetahuan untuk menyelesaikan masalah-masalahnya. Seperti Gogarten,

\footnotetext{
${ }^{15}$ Ibid., 55.

${ }^{16}$ Paul Enns, The Moody Hanbook of Theology (Malang: SAAT, 2004), 233.

${ }^{17}$ Hadiwijono, Pemikiran Reformatoris Abad Ke-20, 59.

${ }^{18}$ Lane, Runtut Pijar Sejarah Pemikiran Kristiani, 229.
} 
ia mendukung penyataan bahwa Kristus adalah hadir di dalam dunia yang tidak religius ini, tetapi dengan cara yang berbeda. Kristus harus dilihat sebagai Tuhan orang yang tak beragama. Pandangannya tentang gereja juga sangat ekstrim. Gereja hanya disebut gereja jika ia eksis untuk yang lain dan tidak lagi eksklusif cakupan operasionalnya. Keterlibatan gereja di dalam masalah sekular manusia, bukan mendominasi melainkan menolong dan melayani. Gereja tidak perlu lagi memikirkan urusan-urusan keagamaannya sendiri, tetapi melayani dunia dengan cara yang sekular. ${ }^{19}$ Kalau perlu semua properti gereja diserahkan kepada mereka yang membutuhkan.

Sebuah buku berjudul Honest to God karangan JAT Robinson diterbitkan pada tahun 1963. Robinson adalah seorang uskup di Woolwich, Inggris. Buku ini mendorong pemikiran yang lebih serius lagi tentang teologi sekularisasi. Robinson adalah seorang teolog dari Inggris yang sangat dipengaruhi oleh Bonhoeffer soal kekristenan tanpa agama. Robinson juga setuju dengan Rudolf Butlman yang menggagas demitologisasi Kitab Suci. Bahkan mendukung pandangan Tillich yang mengatakan bahwa Allah adalah dasar keberadaan manusia di mana keberadaan obyektif manusia adalah suatu bentuk keprihatinan yang paling tinggi.

Dalam pandangan Robinson, Allah bukanlah transenden yang ada di atas sana, yang tertinggi dan tak terjangkau. ${ }^{20}$ Allah ada di dalam kita sebagai bagian paling dasar keberadaan kita. $^{21}$ Allah ada di dalam dunia bukan sebagai eksistensi yang mandiri. Bahkan istilah Allah sendiri dapat dipakai bergantian dengan kata alam semesta. ${ }^{22}$ Konsep sekularisasi kekristenan yang ditawarkannya sebagai sebuah pendekatan baru adalah, menyamakan Allah dengan alam semesta. Hal-hal yang bersifat agamawi digantikan dengan keterlibatan sosial di tengah masyarakat. Orang kristen yang mengasihi Allah, dituntut untuk menjadi lebih peka bagi orang-orang lapar, yang tanpa sandang serta yang terpenjara. Ini adalah bentuk panggilan kekristenan di dunia sekuler yang oleh Robinson disebut sebagai panggilan kekudusan melalui penyembahan. ${ }^{23}$

Seperti pandangan Bonhoeffer tentang gereja, Robinson setuju bahwa gereja harus dipisahkan dari pandangan kultis dan dibebaskan dari kekuasaan sahadat. Gereja adalah pelayan di tengah-tengah dunia yang sekuler dengan menjadikan diri sebagai persekutuan kenabian. Secara radikal Robinson mengatakan bahwa dunia adalah bait Allah dan gereja

\footnotetext{
${ }^{19}$ Ibid., hal. 230.

${ }^{20}$ Smith, A Handbook of Contempporary Theology, 173.

${ }^{21}$ Hadiwijono, Pemikiran Reformatoris Abad Ke-20, 115.

${ }^{22}$ Enns, The Moody Hanbook of Theology, 222-223.

${ }^{23}$ Smith, A Handbook of Contempporary Theology, 174.
} 
menjadi alat pelayanan di dalam rumah Allah. Sependapat dengan teori Gogarten, Robinson setuju bahwa gereja dan orang kristen bertugas untuk mengubah sekularisme dan humanisme di Barat menjadi sekularisasi yang sebenarnya ${ }^{24}$.

Harvey Cox, seorang teolog protestan menulis sebuah buku yang diberinya judul The Secular City pada tahun $1965 .^{25}$ Sub judul buku ini adalah tentang Sekularisasi dan urbanisasi dalam perspektif teologi. Buku ini menimbulkan perdebatan karena Cox mensistematiskan teologi sekularisasi, bahkan memberikan justifikasi teologis melebihi konsep dari para pendahulunya. Menurut Cox, sekularisasi adalah pembebasan manusia dari proteksi agama dan metafisika, pengalihan dari alam lain kepada dunia ini. ${ }^{26}$ Cox menyetujui gagasan bahwa pusat modernitas adalah dunia dan bukan agama. Cox juga memandang adanya perbedaan yang sangat signifikan antara sekularisasi dengan sekularisme. Menurutnya sekularisme adalah nama sebuah ideologi yang tertutup. Sedangkan sekularisasi akan membebaskan masyarakat dari kontrol agama dan pandangan-alam metafisik yang tertutup (closed metaphysical worldviews). Sekularisme akan membahayakan keterbukaan dan kebebasan yang dihasilkan oleh sekularisasi. Seperti konsep Gogarten, sekularisme perlu dikawal dan diawasi agar tidak berkembang menjadi ideologi negara.

Bobot teologi dari sekularisasi dalam argumentasi Cox adalah penekanan bahwa sekularisasi berakar dari kepercayaan Alkitab. ${ }^{27}$ Pada taraf tertentu, ia adalah hasil otentik dari implikasi kepercayaan Bible terhadap sejarah Barat. ${ }^{28}$ Terdapat tiga komponen penting dalam Alkitab yang menjadi kerangka dasar kepada sekularisasi, yaitu: disenchantment of nature; yang dikaitkan dengan penciptaan (Creation), desacralization of politics; dengan migrasi besar-besaran (Exodus) kaum Yahudi dari Mesir dan deconsecration of values; dengan Perjanjian Sinai (Sinai Covenant). ${ }^{29}$ Dengan menjustifikasi sekularisasi berasal dari ajaran Alkitab, Cox menyimpulkan bahwa sekularisasi adalah konsekuensi sah dari keimanan Kristiani. Manusia pra-sekular seperti bangsa Sumeria, Mesir kuno dan Babilonia memercayai bahwa dunia ini adalah mistis. Dewa-dewa matahari, bintang-bintang, sungai-sungai,

\footnotetext{
${ }^{24}$ Hadiwijono, Pemikiran Reformatoris Abad Ke-20, 121.

${ }^{25}$ Sejak pertama kali dicetak tahun 1964, buku The Secular City telah mencapai tiras penjualan melebihi satu juta eksemplar yang tidak pernah diprediksikan oleh penulis dana penerbitnya. Buku itu memunculkan banyak perdebatan baik di kalangan protestan maupun katolik mengenai isyu peranan gereja di dalam dunia modern. Pemikiran Harvey Cox tentang sekularisasi banyak dipengaruhi oleh para pendahulunya seperti Friedrich Gogarten, Paul van Buren, R. Gregor Smith, C. A. van Peursen, dan Dietrich Bonhoeffer. Keunggulan Cox adalah pembahasan sekular-nya tampak lebih popular dan terformulasi dengan lebih sistematis.

${ }^{26}$ Harvey Cox, The Secular City: Secularization and Urbanization in Theological Perspective (New York: The Macmillan Company, 1967), 15.

${ }^{27}$ Smith, A Handbook of Contempporary Theology, 168.

${ }^{28} \mathrm{Cox}$, The Secular City: Secularization and Urbanization in Theological Perspective, 18.

${ }^{29}$ Ibid, 19-32.
} 
misalnya, diyakini memiliki kekuatan mistis. Matahari, bulan sertabintang dianggap seperti makhluk setengah-Tuhan. Posisi sejarah (history) berada di bawah kosmologi (cosmology); masyarakat di bawah alam (nature); zaman (time) di bawah ruang (space); dan Tuhan serta manusia adalah bagian dari alam.

Pandangan Yahudi tentang Penciptaan merupakan awal penolakan terhadap kepercayaan kepada mistis. Inilah permulaan dari pengosongan nilai-nilai mistis dari alam. Matahari, bulan dan bintang serta alam seisinya merupakanciptaan Yahweh ${ }^{30}$. Bagi Cox, pengosongan dunia dari nilai-nilai ruhani dan agama merupakan disenchantment of nature ${ }^{31}$. Pengosongan itu adalah prasyarat mutlak (an absolute precondition) yang memberi tempat bagi perkembangan sains. Jadi, jika dunia ini dikosongkan dari tradisi atau agama yang menyatakan ada kekuatan supranatural yang menjaga dunia ini, sains akan bisa berkembang dan maju, dan demikian sebaliknya. Manusia harus mengeksploitasi dunia seoptimal mungkin,tanpa perlu dibatasi oleh pandangan-alam agama apa pun. Dunia modern yang sudah maju dalam sains tidak lagi membutuhkan penjelasan bahkan campur tangan ajaran atau norma agama. Sains dan kemajuannya dianggap mampu menjawab semua tantangan dan persoalan yang ada.

Dalam terminologi Cox, peristiwa eksodusnya orang-orang Yahudi dari Mesir adalah satu bentuk desacralization of politics. Peristiwa sejarah tersebut adalah sebuah peristiwa perubahan sosial, yang mungkin sekarang ini disebut sebagai penentangan sipil (civil disobedience) terhadap Firaun. Peristiwa itu adalah peristiwa nasionalisme. ${ }^{32}$ Hal itu membuktikan pengajaran Alkitab bahwa politik tidaklah sakral (Desacralization of politics). Unsur-unsur rohani dan agama harus disingkirkan dari politik. Peran ajaran agama ke atas institusi politik juga harus disingkirkan. Ini menjadi syarat untuk melakukan perubahanpolitik dan sosial. Segala macam kaitan antara kuasa politik dengan agama dalam masyarakat tidak boleh berlakudalam masyarakat sekular.

Sekularisasi juga terjadi dalam kehidupan dengan merelatifkan semua nilai-nilai kemanusiaan (deconsecration ofvalues). Jadi, kebenaran adalah relatif dan tidak ada nilai yang mutlak. Karena perspektif seseorang selalu dipengaruhioleh faktor sosial dan budaya, maka tidak ada seorang pun yang berhak memaksakan sistem nilainya ke atas orang lain. Oleh karena wahyu langit terjadi dalam sejarah, maka manusia sekular memercayai bahwa

\footnotetext{
${ }^{30}$ Ibid, 19-20.

${ }^{31}$ Istilah ini sebenarnya adalah terjemahan die Entzauberung der Welt, sebuah istilah yang dipopulerkan oleh Max Weber, seorang sosiolog Jerman.

${ }^{32}$ Harls Evan Siahaan, "Mengajarkan Nasionalisme Lewat Momentum Perayaan Paskah: Refleksi Kritis Keluaran 12:1-51," DUNAMIS (Jurnal Teologi dan Pendidikan Kristiani) Vol 1, no. 2 (2017): 39-54, www.sttintheos.ac.id/e-journal/index.php/dunamis.
} 
wahyu langit dibentuk oleh kondisi sosial dan politik tertentu. Jadi, sebenarnya semua sistem nilai terbentuk oleh sejarah yang mengikuti ruang dan waktu dan tertentu. Bagi Cox, manusia sekular akan menganggap konsep Tuhan sebagai persoalan sosiologis, politis sekaligus teologis. Dalam tatanan masyarakat, Tuhan hadir melalui peristiwa-peristiwa perubahan sosial, Dia sudah lebih dulu hadir dalam budaya dan sejarah sebelum agama diperkenalkan. ${ }^{33}$ Hubungan yang harmonis antara manusia dengan manusia, misalnya, mengindikasikan kehadiran Tuhan. Jadi fokus dalam teologi sekularisasi yaitu menjadikan manusia sebagai pembahasan utama, menggantikan teologi tradisional yang masih menekankan Tuhan. Dengan teologi sekular, Tuhan, hukum Tuhan dan agama harus dimanusiawikan.

\section{Evaluasi}

Rudolf Bultmann (1884-1976) adalah seorang teolog yang dikenal dengan kritik bentuk-nya. Konsepnya tentang demitologisasi Injil telah memberi ruang bagi sekularisasi mencapai bentuknya dalam masyarakat modern. Bultmann mengatakan bahwa catatan Injil adalah kumpulan mitos tentang eksistensi manusia yang sama sekali jauh dari aspek kesejarahan. Itu sebabnya perlu dilakukan usaha demitologisasi, supaya Injil bisa dipakai dan dipahami dalam konteks masa kini. Hal inilah yang kemudian menjadi inspirasi bagi para teolog sekularisasi yang mencoba menyusun kerangka teologi baru dengan melakukan pemisahan di dalam Injil terhadap hal-hal yang tidak sesuai atau diragukan kebenaran-nya secara ilmu pengetahuan.

Teologi sekularisasi memberikan kebebasan masyarakat dari belenggu dan ikatan agama; dan menjadikan dunia sebagai pusat segala sesuatu. Hal ini pula yang sekaligus menjadi kelemahan teologi sekularisasi. Selain bahaya penyimpangan ke arah sekularisme dan ekstrimnya ke arah atheisme, teologi sekularisasi dapat membuat manusia kehilangan pandangan terhadap Allah yang berdaulat "di atas sana" terhadap kehidupan manusia "di bawah sini". Teologia sekularisasi juga dapat mengarah pada jebakan humanis. Seperti dikatakan oleh Robinson, bahwa dalam konteks teologi sekularisasi, pertanyaan "Bagaimana saya dapat menemukan Allah yang pemurah?" harus diganti dengan pertanyaan "Bagaimana saya dapat menemukan sesama yang pemurah?" 34 Usaha para teolog ini untuk membentuk kembali kekristenan tanpa Allah adalah satu bentuk spiritualitas baru. ${ }^{35}$ Para teolog ini

\footnotetext{
${ }^{33}$ Fransiskus Randa et al., "STUDI ETNOGRAFI: AKUNTABILITAS SPIRITUAL PADA ORGANISASI GEREJA KATOLIK YANG TERINKULTURASI BUDAYA LOKAL,” Jurnal Akuntansi Multiparadigma Vol 2, no. 1 (2011).

${ }^{34}$ Hadiwijono, Pemikiran Reformatoris Abad Ke-20, 81.

${ }^{35}$ Pandangan ini dapat ditemukan dalam buku God Without Religion yang ditulis oleh Sankara Saranam. Sudah diterbitkan dalam bahasa Indonesia oleh Gramedia (2009).
} 
rupanya tidak sadar bahwa, sejarah peradaban manusia, meskipun teori Allah mati sudah dikumandangkan dari generasi ke generasi, ada satu kebutuhan manusia akan Allah yang terlihat dari munculnya gerakan spiritualitas dan keberadaan agama-agama baru, yang cenderung mengarah pada panteistik. ${ }^{36}$ Hal itu membuktikan bahwa manusia memiliki satu kesadaran religi bahwa Allah itu ada dan manusia mencari-Nya.

Dalam teologi sekularisasi, eksistensi Allah, Alkitab dan manusia serta relasi di antara ketiganya, tidak mendapat tempatnya sama sekali. Apalagi jika hal tersebut berhubungan dengan sesuatu yang supranatural. Demikian halnya gereja, perannya mengalami reduksi sedemikian rupa sehingga tidak lagi dianggap sebagai "umat pilihan Allah" yang terpisah dari dunia, yang dipilih oleh Kristus; tempat persekutuan; pemuridan dan pengenalan akan Allah, sebagai mempelai-Nya, melainkan berhenti pada satu fungsi pelayanan semata di dalam dan di tengah dunia. Pandangan teologi sekularisasi tentang eskatologi Alkitab, mengenai hal kerajaan yang akan datang, tidak diterima. Kerajaan yang dimaksud adalah kerajaan yang sekarang dan hadir pada masa kini. Demikian halnya penekanan teologi ini yang difokuskan pada akal budi manusia dan kemampuan penalarannya, sangat bertentangan dengan ajaran Alkitab tentang Allah yang menjadi sumber segala sesuatu ${ }^{37}$. Nalar bukanlah wewenang tertinggi. Persepsi manusia yang telah jatuh ke dalam dosa mengenai kebenaran sangat terbatas, khususnya dalam bidang moral dan spiritual. ${ }^{38}$

Kendati demikian, teologi sekularisasi sebagai satu wujud teologi kontemporer telah berusaha melakukan tugasnya untuk membuat dunia ini tidak mengarah pada sekularisme dan mengupayakan berbagai usaha untuk membuat dunia bisa lebih mengenal Allah, gereja, Alkitab dan kekristenan dengan caranya sendiri. Khususnya mengenal penderitaanNya untuk menanggung dosa manusia dengan "membeli" pengampunan lewat karya Salib. ${ }^{39}$ Teologi sekularisasi dapat menjadi refleksi tentang tugas manusia yang sesungguhnya.

\section{Kesimpulan}

Teologi sekularisasi merupakan bentuk aktualisasi pemikiran modern yang mencoba menerapkan nilai-nilai kekristenan dalam konteks dunia yang lebih luas, yang terlepas dari hegemoni agama dan dogmatikanya. Teologi ini muncul sebagai sebuah respon terhadap persoalan-persoalan mistik dan dogmatis yang menguasai semua sendi kehidupan manusia,

\footnotetext{
${ }^{36}$ William Lane Craig, "PANTHEISTS IN SPITE OF THEMSELVES? PANNENBERG, CLAYTON, AND SHULTS ON DIVINE INFINITY," American Theological Inquiry Vol 5, no. 1 (2012): 3-23, http://www.atijournal.org.

${ }^{37}$ Harvie M Conn, Teologia Kontemporer (Malang: SAAT, 2008), 83-85.

${ }^{38}$ Bruce Milne, Mengenali Kebenaran (Jakarta: BPK Gunung Mulia, 1996), 32.

${ }^{39}$ Sonny Eli Zaluchu, "Penderitaan Kristus Sebagai Wujud Solidaritas Allah Kepada Manusia," DUNAMIS (Jurnal Teologi dan Pendidikan Kristiani) 2, no. 1 (2017): 61-74.
} 
sehingga manusia tidak menemukan jati dirinya secara manusiawi dan alamiah. Teologi sekularisasi berbeda dengan sekularisme. Namun demikian, teologi sekularisasi dapat menjadi refleksi bagi gereja masa kini yang terlalu sibuk dengan urusan dogmatika dan gerejanya, tanpa memedulikan dunia sekular yang menjadi ladang dan tanggung jawabnya.

\section{Referensi}

Berger, Peter L. The Sacred Canopy: Elements of A Sociological Theory of Religion. New York: Doubleday \& Company, 1969.

Conn, Harvie M. Teologia Kontemporer. Malang: SAAT, 2008.

Cox, Harvey. The Secular City: Secularization and Urbanization in Theological Perspective. New York: The Macmillan Company, 1967.

Craig, William Lane. "PANTHEISTS IN SPITE OF THEMSELVES? PANNENBERG, CLAYTON, AND SHULTS ON DIVINE INFINITY." American Theological Inquiry Vol 5, no. 1 (2012): 3-23. http://www.atijournal.org.

Dobbelaere, Karel. "The Secularization of Society? Some Methodological Suggestions." In Secularization and Fundamentalism Reconsidered: Religion and the Political Order, edited by Jeffrey K. Hadden and Anson Shupe. New York: Paragon House, 1989.

Enns, Paul. The Moody Hanbook of Theology. Malang: SAAT, 2004.

Fauzan. "SEKULARISASI DALAM PANDANGAN HARVEY COX." Kalam: Jurnal Studi Agama dan Pemikiran Islam Vol 6, no. 2 (2012): 251-272.

Hadiwijono, Harun. Pemikiran Reformatoris Abad Ke-20. Jakarta: BPK Gunung Mulia, 2004. Jun, Chul Min. "The Paradigm Shift of Practical Theology and Theological Practice to Overcome Modernism and Postmodernism." Pacific Science Review (2015): 1-11.

Lane, Tony. Runtut Pijar Sejarah Pemikiran Kristiani. Jakarta: BPK Gunung Mulia, 2005.

Milne, Bruce. Mengenali Kebenaran. Jakarta: BPK Gunung Mulia, 1996.

Prayetno, Budi. "KONSEP SEKULARISASI DALAM PEMIKIRAN NURCHOLISH MADJID.” Sulesana: Jurnal Wawasan Keislaman Vol 11, no. 2 (2017): 1-14.

Randa, Fransiskus, Iwan Triyuwono, Unti Ludigdo, and Eko Ganis Sukoharsono. "STUDI ETNOGRAFI: AKUNTABILITAS SPIRITUAL PADA ORGANISASI GEREJA KATOLIK YANG TERINKULTURASI BUDAYA LOKAL.” Jurnal Akuntansi Multiparadigma Vol 2, no. 1 (2011).

Siahaan, Harls Evan. "Mengajarkan Nasionalisme Lewat Momentum Perayaan Paskah: Refleksi Kritis Keluaran 12:1-51." DUNAMIS (Jurnal Teologi dan Pendidikan Kristiani) Vol 1, no. 2 (2017): 39-54. www.sttintheos.ac.id/e-journal/index.php/dunamis.

Smith, David L. A Handbook of Contempporary Theology. Grand Rapids: Baker Books, 1992.

Wiryadinata, Halim. "An Evaluation Of Liberation Theology in The Light Of Its Praxis." KURIOS (Jurnal Teologi dan Pendidikan Agama Kristen) 1, no. 1 (2013): 1-10.

Zaluchu, Sonny Eli. "Penderitaan Kristus Sebagai Wujud Solidaritas Allah Kepada Manusia." DUNAMIS ( Jurnal Teologi dan Pendidikan Kristiani ) Vol 2, no. 1 (2017): 61-74. 